\title{
Role of refractory elements in near-alpha titanium alloys on high temperature mechanical properties
}

\author{
Z. Huvelin ${ }^{\mathrm{a}}$, C. Gouroglian ${ }^{\mathrm{a}}$, N. Horézan ${ }^{\mathrm{a}}, \mathrm{S}$. Naka ${ }^{\mathrm{a}}$ \\ a DMAS, ONERA, Université Paris Saclay F-92322 Châtillon - France \\ * zhao.huvelin@onera.fr
}

\begin{abstract}
$\underline{\text { Abstract }}$
The effect of Tungsten (W), Tantalum (Ta) and simultaneous addition of Germanium (Ge) and Silicon (Si) on the microstructure evolution, tensile and creep properties of the near-alpha alloy Ti-5.7Al-3.9Sn-3.7Zr-0.7Nb-0.5Mo-0.35Si-0.05C have been investigated at high temperatures up to $650^{\circ} \mathrm{C}$. Microstructural characterizations following solution treatment at $1050^{\circ} \mathrm{C}$ for 2 hours with oil quenching and aging treatment at $700^{\circ} \mathrm{C}$ for 2 hours followed by air cooling, highlighted that the additions of refractory elements such as $\mathrm{W}$ and $\mathrm{Ta}$ led to a decrease of both the volume fraction of the primary alpha phase $\left(\mathrm{a}_{\mathrm{p}}\right)$ and its average size. Tensile tests performed up to $650^{\circ} \mathrm{C}$ revealed a significant improvement in tensile strength with additions of $\mathrm{W}$ and Ta, even though a decrease of ductility has been also detected. Creep tests carried out at $600^{\circ} \mathrm{C}$ under a constant stress of $200 \mathrm{MPa}$ pointed out that, refractory elements, Ge and Si have a beneficial effect on both primary and steady-state creep strain rates.
\end{abstract}

\section{Introduction}

Near-alpha titanium alloys are promising candidates for aerospace applications owing to their high specific strength, good corrosion resistance and high temperature resistance [1]. The latest high temperature titanium alloys, such as IMI834 [2], Ti1100 [3], BT36 [4] or Ti600 [5], have been developed for high temperature application up to $600^{\circ} \mathrm{C}$ as compressor disk and blade for gas turbines of advanced jet engines, but in-service these alloys cannot be used above $550^{\circ} \mathrm{C}$. Over the past decades numerous research works have been carried out to find suitable strengthening method to improve high temperature properties up to or even higher than $600^{\circ} \mathrm{C}$. Alloying is one of the fundamental methods to improve the high temperature mechanical properties of titanium alloys. Conventional near-alpha Ti alloys are strengthened by fine alpha2 phase with $\mathrm{DO}_{19}$ structure and intermetallic silicides [78]. Up to now, numerous works were focused on the influence of alpha stabilizing alloying elements such as $\mathrm{Ga}, \mathrm{Sn}, \mathrm{Hf}$ and $\mathrm{Zr}$ on the high temperature mechanical properties of the near-alphaa titanium alloys [9-10, 12]. These studies demonstrated that the solid solution strengthening and the formation of a phase are effective in improving high temperature strength, but degrade the ductility of the material [10-11] probably due to the lower symmetry of its $\mathrm{DO}_{19}$ crystal structure. The effect of silicon addition was also extensively studied to increase high temperature tensile and creep strength of near-a and $a+b$ titanium alloys [9, 13-14]. This is achieved by solid solution strengthening and precipitation strengthening. However, it has been reported that silicide precipitation also decreases the ductility $[13,15-16]$ because fracture occurs due to the linkage of the cracks that are initiated in the regions where the slip bands intersect with silicide particles [17]. Recently, Kitashhima et al.[6] evaluated the effect of Ge addition on the tensile properties, impact toughness and fracture behavior of a near-alpha titanium alloy because it has several similar aspects to Si. For example, Ge and $\mathrm{Si}$ are completely soluble, Ge can form $\mathrm{Ti}_{5} \mathrm{Ge}_{3}$ germanide having the same crystal structure as $\mathrm{Ti}_{5} \mathrm{Si}_{3}$ silicide. Moreover the solubility of Ge in the alpha phase is higher than that of Si [23]. Results of their studies suggest a significant increase in YS and UTS at room temperature with Ge additions. Moreover, the ductility of the alloys increases with Ge content, especially at high temperatures. However, hardly any literature deals with the effects of refractory elements such as W or Ta on high temperatures properties of near-alpha titanium alloys although these elements are well known to be effective for high temperature tensile and creep strength in titanium aluminide system [18] due to their low rate of diffusion and high melting point.

In the present study, the effect of refractory elements additions in a Ti-834 type alloy on microstructure evolution, high temperature tensile strength and creep properties was investigated.

\section{Materials and experiments}

Ti-834M alloy with modified composition was made from high purity Ti-sponge and alloying elements, melted by vacuum arcfurnace. Subsequently, the $30 \mathrm{~cm}^{3}$ ingot was then hot rolled to $13 * 13 \mathrm{~mm}^{2}$ square cross-section bar at a temperature in the alpha+beta domain. A second square cross-section bar Ti-834R, was re-melted from an ingot with a standard chemical composition of Ti-834 alloy and then hot rolled in the same conditions. Finally, a forged slice in Ti-834D with a diameter of 217 $\mathrm{mm}$ and thickness of $13 \mathrm{~mm}$ was provided by Timet. The bimodal microstructure of the alloy in as-received state is presented in Figure $1 \mathrm{~b}$. The alloy designation and chemical composition are shown in Table 1.

Table 1 - Alloys designation and chemical composition

\begin{tabular}{ccccccccc}
\hline $\begin{array}{c}\text { Alloy } \\
\text { designation }\end{array}$ & Al & Sn & Zr & Mo & Nb & $(\mathrm{Ta}+\mathrm{W}+\mathrm{Ge})$ & $(\mathrm{Si}+\mathrm{C})$ \\
\hline
\end{tabular}

(C) The Authors, published by EDP Sciences. This is an open access article distributed under the terms of the Creative Commons Attribution 


\begin{tabular}{cccccccc}
$\mathbf{8 3 4 M}$ & 5.8 & 3.95 & 3.5 & - & - & 3.7 & 0.15 \\
$\mathbf{8 3 4 D} / \mathbf{R}$ & 5.7 & 3.97 & 3.68 & 0.52 & 0.68 & - & 0.4 \\
\hline
\end{tabular}

beta-transus temperatures of $834 \mathrm{M}$ and $834 \mathrm{D}$ alloys were determined by Differential Thermal Analysis (DTA) curves and also by solution treating of small samples at temperature ranging $1000^{\circ} \mathrm{C}$ to $1065^{\circ} \mathrm{C}$, followed by oil cooling. Metallographic observations of the as-quenched samples were done to determine the beta-transus temperature at and above which the final microstructure contained no coarse primary alpha phase. beta-transus temperatures of the $834 \mathrm{M}$ and $834 \mathrm{D}$ alloys measured by DTA and metallographic technique are listed in Table 2. All alloys were subjected to solution treatment at $1015^{\circ} \mathrm{C}\left(30^{\circ} \mathrm{C}\right.$ below to betatransus) for $2 \mathrm{~h}$ followed by oil quench and to a subsequent ageing heat treatment of $2 \mathrm{~h}$ at $700^{\circ} \mathrm{C}$ followed by air cooling. Microstructural investigations of as-received and heat treated specimens were performed on a scanning electron microscope (SEM) Zeiss DMS 982. The phase fractions of the primary alpha phase were determined by quantitative analysis of SEM micrographs.

Table 2 - beta-transus temperature of the 834M alloy and 834D

\begin{tabular}{ccc}
\hline beta-transus & DTA & Metallographic Technique \\
\hline $\mathbf{8 3 4 M}$ & $1048 \pm 5^{\circ} \mathrm{C}$ & $1040^{\circ} \mathrm{C}<\mathrm{T}_{\mathrm{b}}<1050^{\circ} \mathrm{C}$ \\
$\mathbf{8 3 4 D} / \mathbf{R}$ & $1045 \pm 5^{\circ} \mathrm{C}$ & $1045^{\circ} \mathrm{C}<\mathrm{T}_{\mathrm{b}}<1055^{\circ} \mathrm{C}$ \\
\hline
\end{tabular}

Specimens for tensile and creep tests were machined from the solution treated and aged bars and slice. The tensile and creep specimens had gauge dimensions of $7 \mathrm{~mm}$ (diameter) and $50 \mathrm{~mm}$ (length). Tensile tests were performed in air at a temperature up to $650^{\circ} \mathrm{C}$ using an Instron 5582 testing machine at a strain rate of $3.6 \times 10^{-4} \mathrm{~s}^{-1}$. The creep tests were conducted until rupture of the specimens at $600^{\circ} \mathrm{C}$ under a constant stress of $200 \mathrm{MPa}$ in air. The tensile fracture modes of the tensile specimens were investigated by SEM.

\section{$\underline{\text { Results and discussions }}$}

\section{Microstructure characterizations}

Figure 1 shows the microstructures, which are perpendicular to the rolling direction and forging direction of 834M and 834D alloys, respectively. The alloys exhibit a bimodal microstructure with primary alpha phase $\left(\mathrm{a}_{\mathrm{p}}\right)$ and beta/alpha lamellar structures $\left(b_{t}\right)$, wherein the dark and bright phases are alpha phase and beta phase, respectively. Due to the rolling process, alpha grains in $834 \mathrm{M}$ alloy have an elongated morphology (Figure 1a) whereas in the forged 834 slice, alpha grains are equiaxed (Figure 1b). The volume fraction of primary alpha phase was estimated at $34 \%$ and $29 \%$ in $834 \mathrm{M}$ and 834 alloys, respectively. This microstructural feature is closely related to the beta-transus temperature.

Figure 1 -Microstructure in as-received state of a) 834M alloy hot-rolled bar and b) 834D alloy forged slice

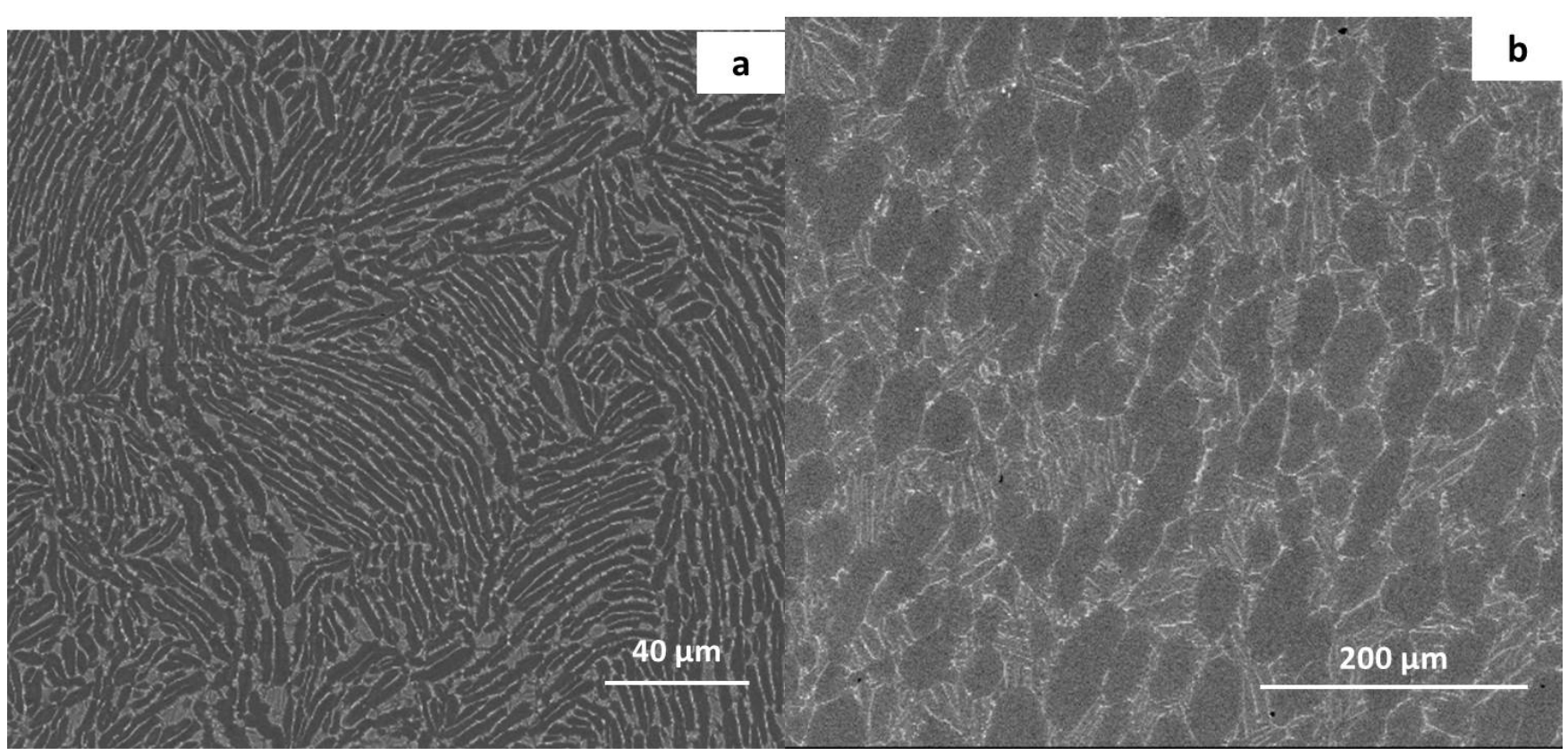

Figure 2 shows the microstructures of heat-treated alloys. It can be seen in 834M and 834D alloys a bimodal microstructure with relatively fine secondary alpha $\left(a_{s}\right)$ lamella in $b_{t}$. Thus, the heat treatment erased partially the initial texture of the hot rolled $834 \mathrm{M}$ alloy. The image analysis from SEM micrographs shows a higher volume fraction of primary alpha phase in 834D alloy, which was estimated at $26.5 \%$, than in $834 \mathrm{M}$ alloy with a volume fraction of $18.2 \%$. The average size of the equiaxed alpha grains was 
estimated at $8.8 \mu \mathrm{m}$ in $834 \mathrm{M}$ alloy against $17.4 \mu \mathrm{m}$ in the $834 \mathrm{D}$ alloy. This result can be explained by the addition of beta stabilizing elements such as Ta or/and W, which are known to have low diffusivity. Thus these elements appear control the diffusional growth process in $834 \mathrm{M}$ alloy. Furthermore, according to Kitashima et al. [6], an addition of Ge can also decrease the volume fraction of primary alpha phase.

Figure 2 - Backscattered electron micrographs of heat-treated a) $834 \mathrm{M}$ and b) $834 \mathrm{D}$ alloys $\left(1015^{\circ} \mathrm{C} / 2 \mathrm{~h} / \mathrm{oil} \mathrm{quenching}\right.$ and $700^{\circ} \mathrm{C} / 2 \mathrm{~h} /$ air cooling)

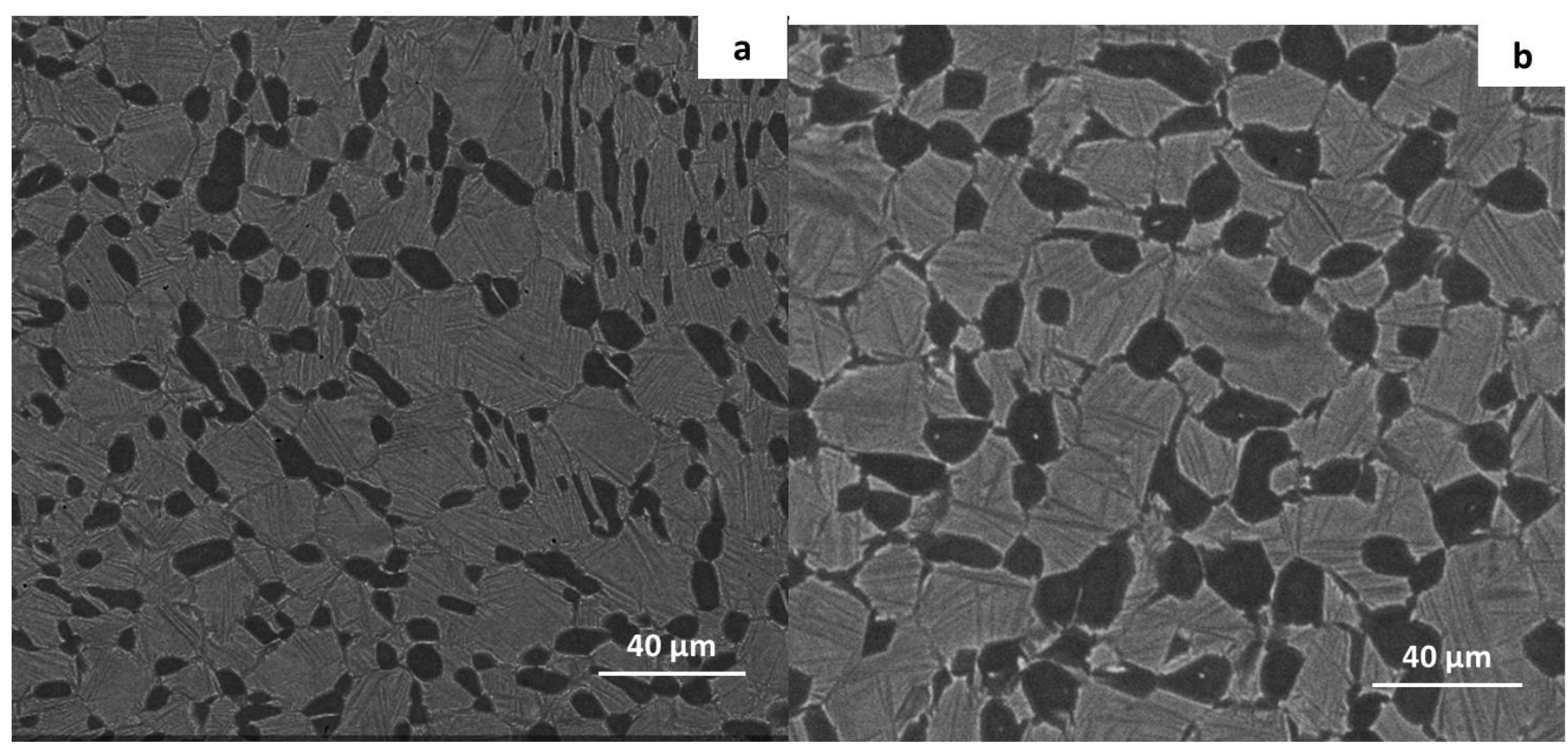

Figure 3 shows the EDS-WDS elemental mapping in heat-treated $834 \mathrm{M}$ alloy. This indicates that the beta stabilizing elements such as Ta and $\mathrm{W}$, are preferentially located in the retained $\mathrm{b}_{\mathrm{t}}$ phase, whereas, $\mathrm{Si}$, Ge and $\mathrm{Zr}$ are concentrated in the small precipitates, located at interfaces between $a_{p}$ and $b_{t}$. These precipitates are pointed out by the white arrows on the Figure 3 .

Figure 3 - EDS-WDS elemental mapping micrographs of the 834M alloy 

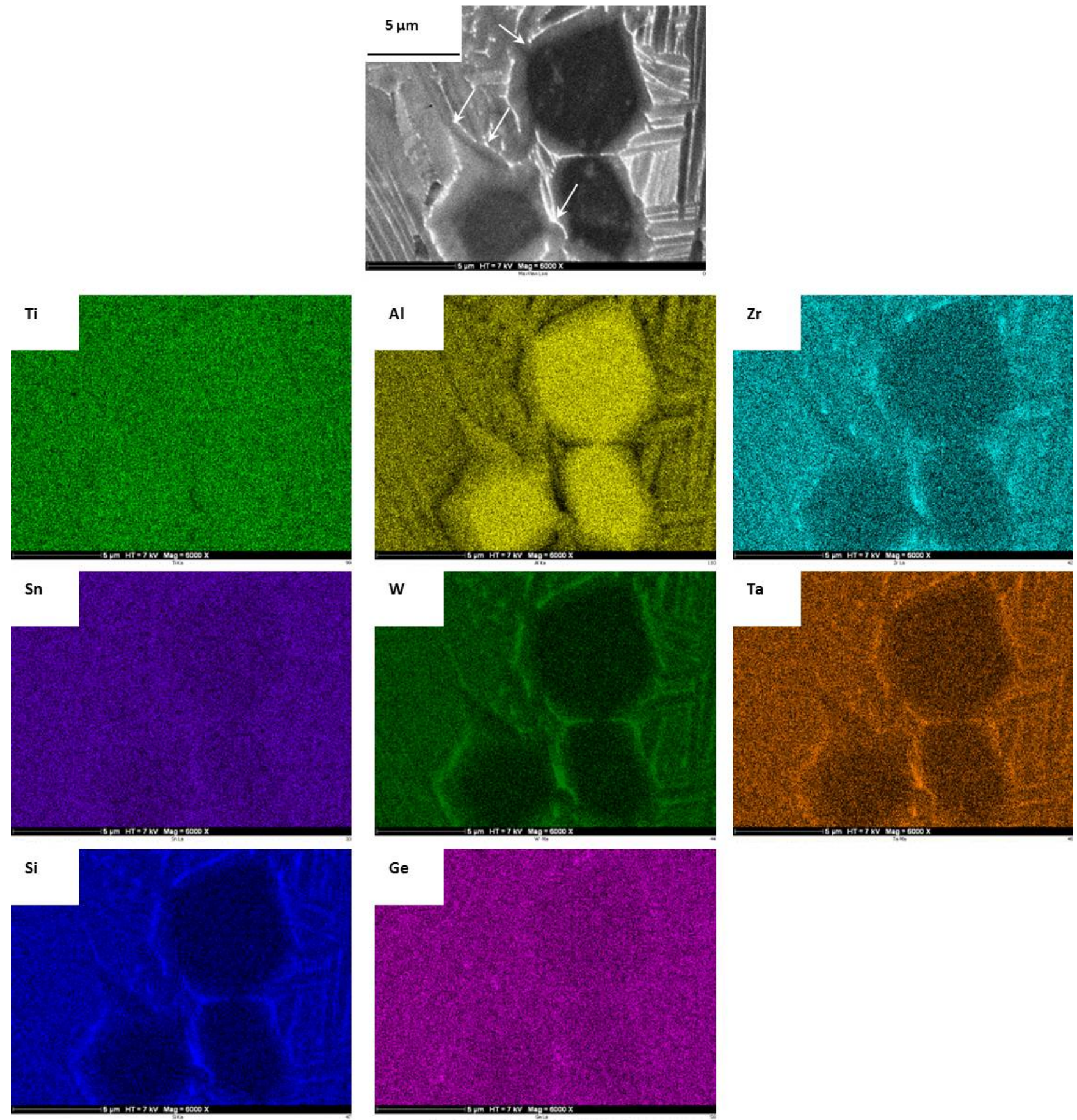

These precipitates were too fines to be resolved at SEM scale. To accurately identify the precipitates nature, their volume fraction and morphology, it would have required an extensive TEM study, which is scheduled for later.

\section{Tensile tests}


Figure 4 displays the tensile stress-strain curves of $834 \mathrm{M}$, and $834 \mathrm{D}$ alloys at $600^{\circ} \mathrm{C}$, and the tensile stress-strain curve of the $834 \mathrm{M}$ specimen tested at $650^{\circ} \mathrm{C}$. At $600^{\circ} \mathrm{C}, 0.2 \%$ yield strength (YS), ultimate tensile strength (UTS) and elongation were 544 $\mathrm{MPa}, 683 \mathrm{MPa}$ and $21 \%$, respectively for $834 \mathrm{M}$ specimen. About the $834 \mathrm{D}$, it displays $0.2 \%$ YS of 456 , UTS of 554 and elongation of $18 \%$. Thus, the alloy with additions of refractory elements $\mathrm{W}$ and Ta presents an increase of $0.2 \%$ YS by almost $19 \%$, of UTS by $23 \%$ and of elongation by $16 \%$. Further, despite the increase of the testing temperature up to $650^{\circ} \mathrm{C}$, the $834 \mathrm{M}$ alloy displays even higher $0.2 \%$ yield strength (YS) and ultimate tensile strength (UTS) than the $834 \mathrm{D}$ sample, which tested at $600^{\circ} \mathrm{C}$ (Figure 4). Surprisingly, the elongation of the $834 \mathrm{M}$ alloy has decreased with increasing tensile test temperature from $600^{\circ} \mathrm{C}$ to $650^{\circ} \mathrm{C}$. Thereby, the additions of refractory elements such as $\mathrm{W}$ and/or Ta increased significantly the high temperatures tensile strength even though the ductility of the material seems to be affected. These results can be attributed to the solid solution strengthening by refractory elements.

Figure 4 - Nominal stress-strain curves of $834 \mathrm{M}$ alloy at 600 and $650^{\circ} \mathrm{C}$ and of $834 \mathrm{D}$ alloy at $600^{\circ} \mathrm{C}$

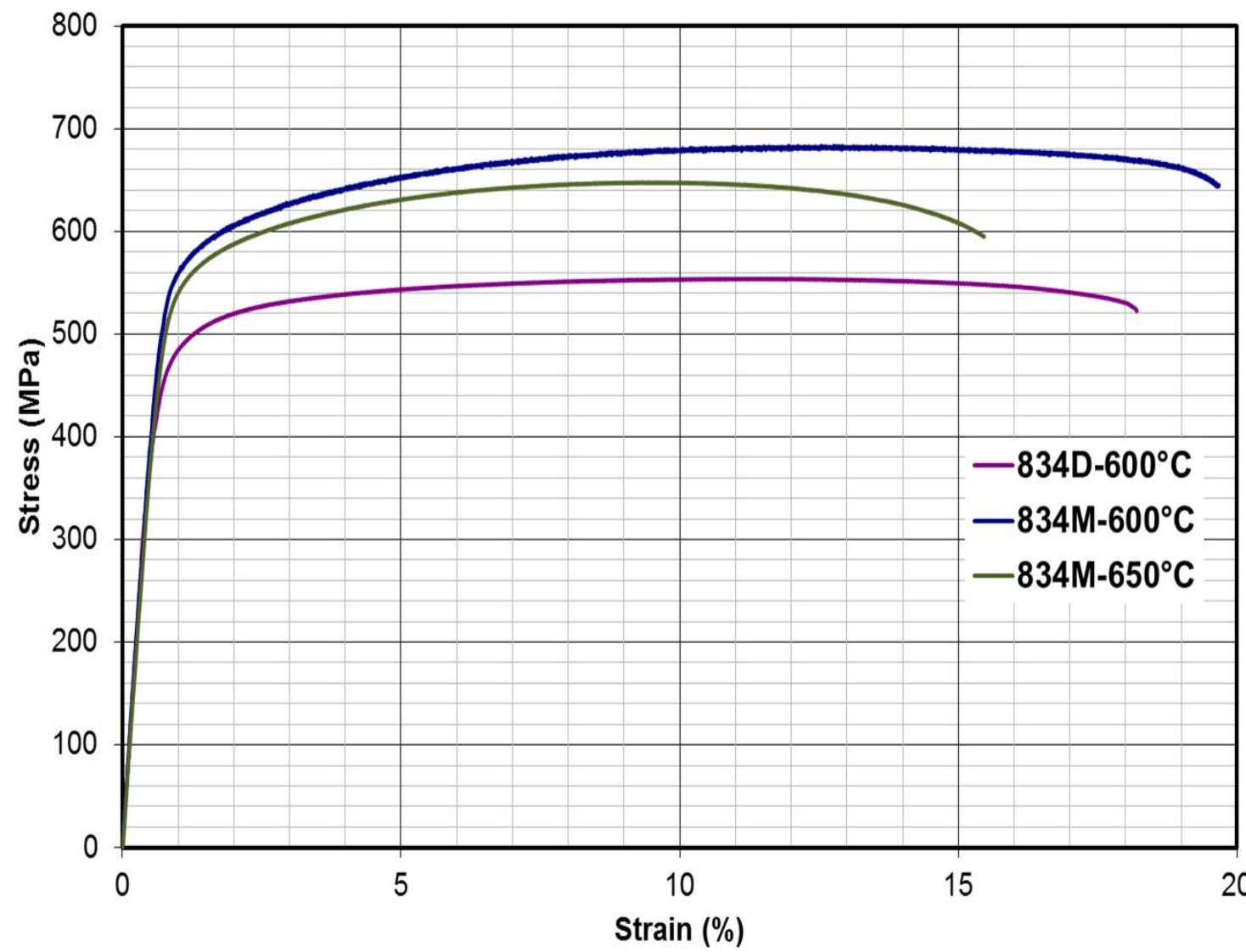

20 The

fractographies of high temperatures

tensile-tested samples are provided in Figure 5. The 834D alloy exhibits a combination of fine dimples and coarse elongated dimples (Figure 5a and b), which indicate that the fracture model of this specimen is ductile fracture primarily. Whereas, the $834 \mathrm{M}$ alloy subjected to ductile fracture and transgranular cleavage fractures which are inferred from the fractographies including some dimples and fracture facets (Figure 5c and d). Thus, the additions of refractory elements lead to the formation of faceted fractures in the regions of colony microstructure, which could explain the decrease of the elongation with the increase of tensile testing temperature of the $834 \mathrm{M}$ alloy.

Figure 5 - Fractographies of $600^{\circ} \mathrm{C}$ tensile tested $834 \mathrm{D}$ a) and b), $834 \mathrm{M} \mathrm{c}$ ) and d) 

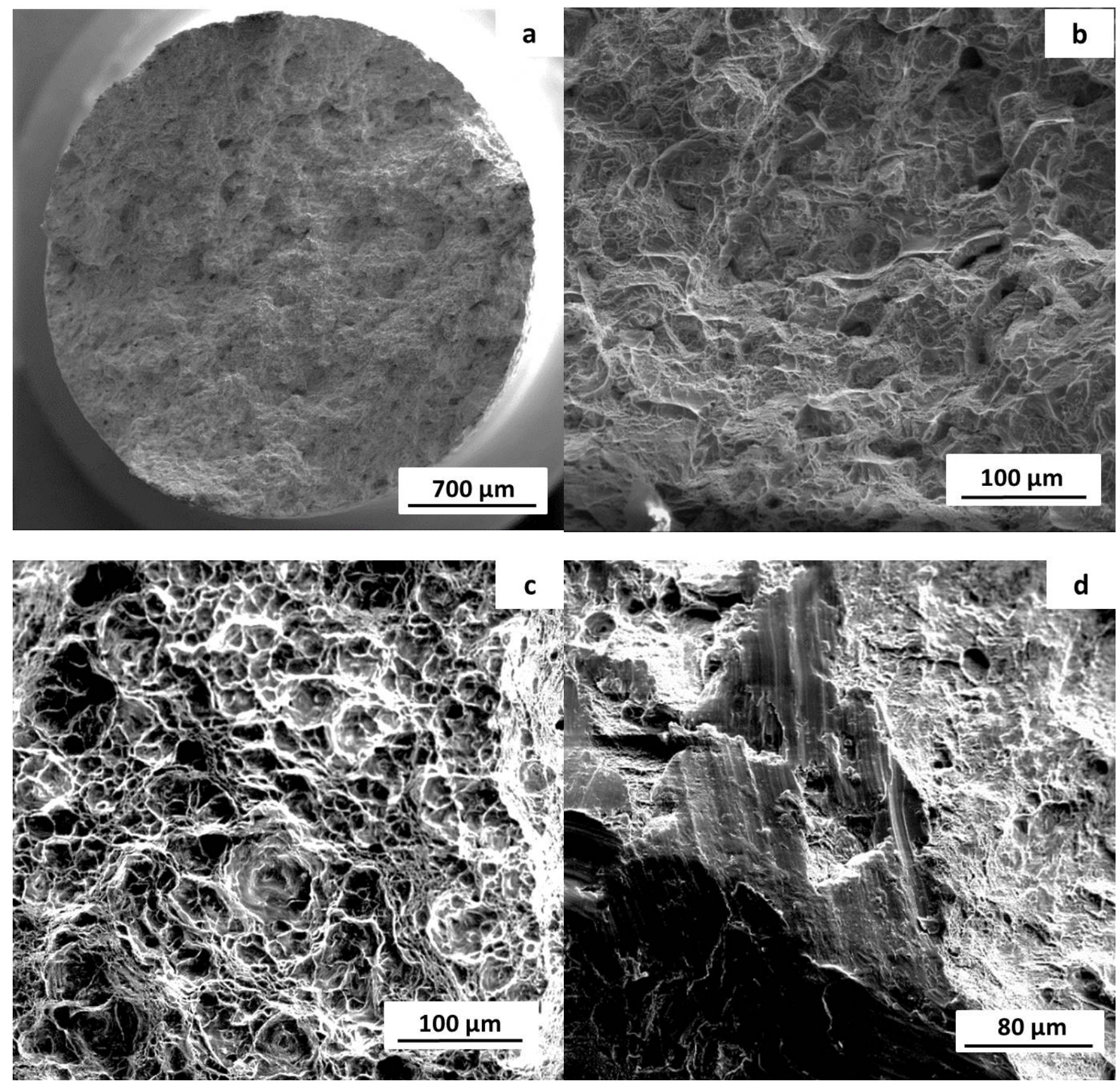

Creep tests

As a reminder, the $834 \mathrm{R}$ alloy is a piece of the $834 \mathrm{D}$ alloy which was hot rolled in the same conditions than $834 \mathrm{M}$ alloy. It was also submitted to the same solution and ageing treatments of $1015^{\circ} \mathrm{C} / 2 \mathrm{~h} /$ oil quenching $+700^{\circ} \mathrm{C} / 2 \mathrm{~h} /$ air cooling. Constant load creep tests were conducted on the $834 \mathrm{M}$ and $834 \mathrm{R}$ alloys at $600^{\circ} \mathrm{C}$ under a stress of $200 \mathrm{MPa}$. Figure 6 shows the creep curves of both $834 \mathrm{M}$ and $834 \mathrm{R}$ samples. These curves indicate clearly the beneficial effect of refractory elements additions on the creep strain resistance since the $834 \mathrm{M}$ alloy displays a steady-state creep rate of $10^{-} 8 . \mathrm{s}^{-1}$ which is 6 times lower than the creep rate of the $834 \mathrm{R}$ alloy. Such result can be related to the amount of $\mathrm{a}_{\mathrm{s}}$ phase. Indeed, extensive studies [19-21] demonstrated that both primary and secondary creep rate increase with the amount of $a_{p}$ phase in the microstructure. Nevertheless, they do postulate that the observed primary alpha effect may be secondary and that the refinement of the transformed beta microstructure resulting from heat treatment closer to the beta-transus may be responsible for the enhanced creep resistance. Our creep results are in accordance with earlier findings of [21] since the $834 \mathrm{M}$ alloy containing a higher volume fraction of $\mathrm{a}_{\mathrm{S}}$ (Figure 2) exhibits the slower steady-state creep rate but also primary creep strain (Figure $6 a$ and $b$ ). Another hypothesis related to the creep deformation mechanism can be put forward. According to Hayes et al. [22], the creep deformation is controlled by dislocation motion and that deformation is clearly dominated by deformation within the alpha phase, especially the diffusion rate of trace elements such as Ni can accelerate notably the creep rate by accelerating the rate of lattice self-diffusion therefore accelerates the rate of dislocation climb. W and Ta are commonly considered to be slow diffusers due to their large atomic seize thus, their additions can slow down the rate of diffusion in alpha phase, especially as $\mathrm{W}$ and Ta are preferentially partitioned in $\mathrm{a}_{\mathrm{S}}$ phase. Concerning the effect of Ge and/or $\mathrm{Si}$ additions on the creep response of the material, a detailed work on high temperature deformation mechanisms is underway in order to clarify their role, and the results will be published elsewhere. 
Figure 6 - a) Steady-state creep curves, b) primary creep curves of $834 \mathrm{M}$ and $834 \mathrm{R}$ under a constant load stress of $200 \mathrm{MPa}$, at $600^{\circ} \mathrm{C}$
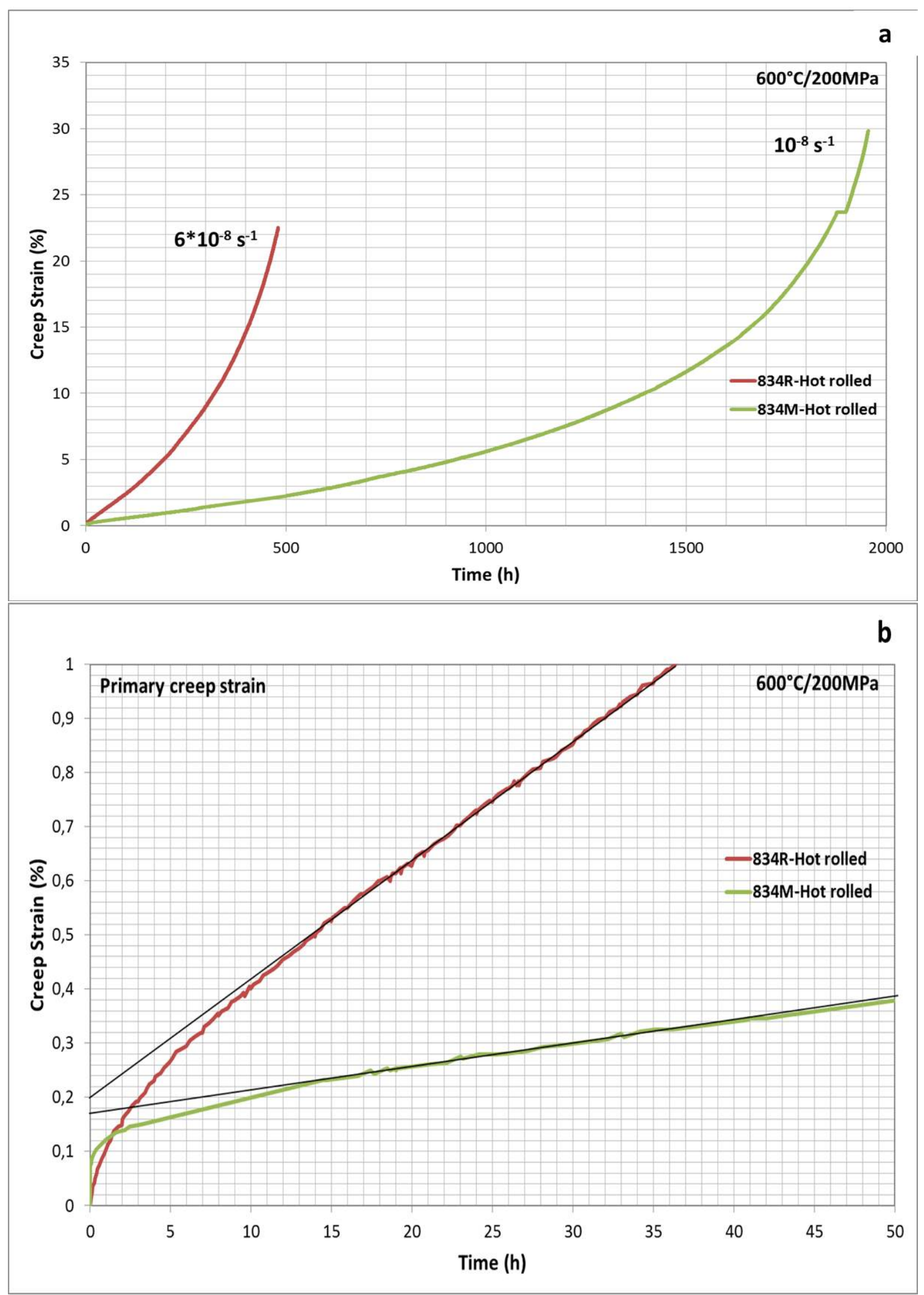

\section{Conclusions}

The current study on the effect of refractory elements combined to Ge and Si additions on the microstructure evolution, high temperature tensile properties and creep resistance of the near-alpha titanium alloy Ti-834 led to following conclusions:

1. Additions of refractory elements such as $\mathrm{W}$ and Ta to Ti-834 alloy resulted in a decrease in the volume fraction of $\mathrm{a}_{\mathrm{p}}$ and also in its average size. This effect has been attributed to the beta stabilizing characteristic of W and Ta. 
2. A pronounced increase in the $0.2 \%$ YS and UTS at $600^{\circ} \mathrm{C}$ and $650^{\circ} \mathrm{C}$ with the additions of refractory elements and Ge and $\mathrm{Si}$ was observed. This has been attributed to the effect of solid solution strengthening by $\mathrm{W}$ and Ta additions. However, a decrease of ductility has been detected in the $834 \mathrm{M}$ alloy. This should be correlated to the formation of faceted fractures in the regions of colony microstructure.

3. The creep resistance is also improved by the combined additions of refractory elements ( $\mathrm{W}$ and $\mathrm{Ta}$ ) and light elements (Ge and $\mathrm{Si}$ ). Not only the steady-state creep rate was reduced by 6 times but also the primary creep rate was improved. This performance can be directly related to the amount of $\mathrm{a}_{\mathrm{s}}$ due to the additions of refractory elements but also to the slow rate of diffusion characteristic of these refractory elements.

\section{$\underline{\text { References }}$}

[1] R.R. Boyer, Mater. Sci. Eng. A213 (1996) 103-114

[2] P. Wanjara, M. Jahazi, H. Monajati, et al. Mater. Sci. Eng. A396 (2005) 50-60

[3] A. Madsen, H. Ghonem, Mater. Sci. Eng. A177 (1994) 63-73

[4] J.M. Cai, M.Y. Hao, et al. J. Mater. Eng. 2 (2000) 10-12

[5] Y. Niu, M.Q. Li, Mater. Sci. Eng. A513-514 (2009) 228-232

[6] T. Kitashima, K.S. Suresh, Y. Yamabe-Mitarai, Mater. Sci. Eng. A597 (2014) 212-218

[7] C. Ramachandra, A.K. Singh, G.M.K. Sarma, Metall. Trans. A 24 (1993) 1273-1280

[8] G. Lütjering, S. Weissmann, Acta Metall. 18 (1970) 785-795

[9] C.E. Shamblen, T.K. Redden, Met. Trans. 3 (1972) 1299-1305

[10] T. Kitashima, Y. Tamabe-Mitarai, S. Iwasaki, S. Kuroda, Metall. Mater. Trans. A 47A (2016) 6394-6403

[11] T. Kitashima, M. Hagiwara, T. Ito et al., Mat. Sci. Forum 941 (2018) 747-752

[12] P.L. Narayana, et al., Mat. Sci. Eng. A 718 (2018) 287-291

[13] H.M. Flower, P.R. Swann, D.R.F. West, Metall. Trans. 2 (1971) 3289-3297

[14] D.F. Neal, S.P. Fox, in F.H. Froes, I.L. Caplan (Eds.), Titanium '92, Scien,ce and Technology, TMS, PA, 1993, 287-294

[15] C. Ramachandra, V. Singh, Metall. Trans. A 16 (1985) 227-231

[16] A. Madsen, H. Ghonem, J. Mater. Eng. Perform. 4 (1995) 301-307

[17] A.P. Woodfield, P.J. Postans, M.H. Loretto, R.E. Smallman, Acta Metall. 36 (1988) 507-515

[18] G.E. Fuchs, Mat. Sci. Eng. A192/193 (1995) 707-715

[19] P.J. Bania, J.A. Hall. Titanium Science and Technology, Deutsche Gesellschaft fur Metallkunde. Germany: Oberursel (1985) 2371

[20] S.R. Seagle, G.S. Hall, H.B. Bomberger, Met Eng Q (1972) 48

[21] K.E. Thiehsen, M.E. Kassner, J. Pollard, D.R. Hiatt, B.M. Bristow. Metall Trans A 24A (1993) 1819

[22] R.W. Hayes, G.B. Viswanathan, M.J. Mills, Acta Mater. 50 (2000) 4965-4980

[23] H. Okamoto, J. Phase equilib. Diff. 33 (2012) 349 